\title{
Transcranial magnetic stimulation as a new approach in medication overuse headache: a pilot study
}

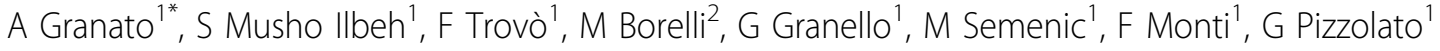 \\ From The European Headache and Migraine Trust International Congress \\ London, UK. 20-23 September 2012
}

\section{Background}

Repetitive TMS (rTMS) is effective in migraine prophylaxis.

\section{Introduction}

To study the efficacy of high-frequency rTMS in medication overuse headache $(\mathrm{MOH})$.

\section{Methods}

A prospective, double-blind, randomized, placebo-controlled trial on patients suffering from $\mathrm{MOH}$ consecutively presenting in a six-month period in the Headache Centre of Trieste was performed. Patients were randomized into the rTMS or the sham-TMS group. Treatment consisted of 10 consecutively TMS sessions delivered on left dorsolateral prefrontal cortex, each session being 10 trains of 2-s duration, separated by 30 -s pause, $20 \mathrm{~Hz}$ frequency, $100 \%$ motor threshold intensity. Demographic and clinical information, MIDAS score, headache days (HD), hours of headache $(\mathrm{HH})$, and symptomatic drugs (SD) in the 3 months before (t1), and in the first (t2) and second month (t3) after stimulation were analysed using SPSS 14.0.

\section{Results}

We enrolled 8 patients (7 F, $1 \mathrm{M}$; mean age $44 \pm 11$ ), four patients undewent rTMS and four sham-TMS. All patients were migraineurs without aura as initial primary headache. We found, in both rTMS and sham-TMS group, no significant difference between the 3 months before and the 2 months after stimulation (rTMS: HD $=22 \pm 6$ t 1 vs $22 \pm$ $11 \mathrm{t} 2$ vs $19 \pm 14 \mathrm{t} 3, \mathrm{HH}=223 \pm 205 \mathrm{t} 1$ vs $219 \pm 198 \mathrm{t} 2$ vs $205 \pm 196 \mathrm{t} 3, \mathrm{SD}=22 \pm 10 \mathrm{t} 1$ vs $18 \pm 7 \mathrm{t} 2$ vs $16 \pm 8 \mathrm{t} 3$;
sham-TMS: $\mathrm{HD}=22 \pm 5 \mathrm{t} 1$ vs $12 \pm 6 \mathrm{t} 2$ vs $13 \pm 8 \mathrm{t} 3, \mathrm{HH}=$ $180 \pm 117 \mathrm{t} 1$ vs $99 \pm 73 \mathrm{t} 2$ vs $97 \pm 28 \mathrm{t} 3, \mathrm{SD}=22 \pm 10 \mathrm{t} 1$ vs $16 \pm 3 \mathrm{t} 2$ vs $17 \pm 4 \mathrm{t} 3)$. MIDAS score significantly reduced in rTMS group at a three-month evaluation $(111 \pm 29$ vs 42 \pm 27 ; $=0.03$ ).

\section{Conclusions}

Our preliminary data suggest that high-frequency rTMS is not useful to treat $\mathrm{MOH}$, however the small sample does not allow to draw safe conclusions.

\section{Author details}

'Department of Medical, Surgical and Health Sciences, Headache Centre, University of Trieste, Trieste, Italy. ${ }^{2}$ Department of Mathematics and Geosciences, University of Trieste, Trieste, Italy.

Published: 21 February 2013

\section{References}

1. Brighina F, Piazza A, Vitello G, Aloisio A, Palermo A, Daniele O, Fierro B: rTMS of the prefrontal cortex in the treatment of chronic migraine: a pilot study. J Neurol Sci 2004, 227(1):67-71.

2. Lipton RB, Pearlman SH: Transcranial magnetic simulation in the treatment of migraine. Neurotherapeutics 2010, 7(2):204-12.

doi:10.1186/1129-2377-14-S1-P168

Cite this article as: Granato et al:: Transcranial magnetic stimulation as a new approach in medication overuse headache: a pilot study. The Journal of Headache and Pain 2013 14(Suppl 1):P168. 